\title{
A pesquisa como princípio pedagógico no contexto do PROEJA
}

\author{
Ana Sara Castaman ${ }^{1}$ \\ Lis Ângela De Bortoli ${ }^{2}$ \\ Angélica Tommasini ${ }^{3}$
}

\begin{abstract}
RESUMO
Este estudo tem por objetivo conhecer os fundamentos que norteiam os Institutos Federais de Educação, Ciência e Tecnologia (IF), de modo a compreender as bases conceituais da pesquisa como princípio pedagógico no contexto do Programa de Integração da Educação Profissional ao Ensino Médio na Modalidade de Educação de Jovens e Adultos (PROEJA). Caracteriza-se como pesquisa exploratória e descritiva, pautando-se em uma perspectiva qualitativa e dialética e pela técnica bibliográfica. Está organizado em 02 (duas) seções: a) aborda as bases conceituais dos IF, enfatizando a pesquisa como um princípio pedagógico; b) apresenta a análise de um relato de experiência do ensino com pesquisa no contexto do PROEJA. Conclui-se que a pesquisa em sala de aula está indissociável do ensino. Assim, há que criar espaços efetivos no PROEJA para que os estudantes possam lidar com elementos inerentes à pesquisa como o questionamento, a construção de argumentos, a produção escrita e o diálogo.
\end{abstract}

PALAVRAS-CHAVE: Pesquisa. Educação de Jovens e Adultos. Ensino.

Research as a pedagogical principle in the context of PROEJA

\footnotetext{
${ }^{1}$ Doutorado em Educação. Instituto Federal de Educação, Ciência e Tecnologia do Rio Grande do Sul, Sertão, Rio Grande do Sul, Brasil. Orcid: http://orcid.org/0000-0002-5285-0694.E-mail: ana.castaman@ @ertao.ifrs.edu.br.

${ }^{2}$ Mestrado em Computação. Instituto Federal de Educação, Ciência e Tecnologia do Rio Grande do Sul, Sertão, Rio Grande do Sul, Brasil. Orcid: http://orcid.org/0000-0001-9414-6569. E-mail: lis.debortoli@ sertao.ifrs.edu.br.

${ }^{3}$ Especialista em Atendimento Educacional Especializado e Educação Especial. Instituto Federal de Educação, Ciência e Tecnologia do Rio Grande do Sul, Sertão, Rio Grande do Sul, Brasil. Orcid: http://orcid.org/0000-0002-5238-6377. E-mail: angelicatommasini1@gmail.com.
} 


\begin{abstract}
This study aims to understand the fundamentals that guide the Federal Institutes of Education, Science and Technology (IF), in order to understand the conceptual bases of research as a pedagogical principle in the context of the Program for the Integration of Professional Education to High School in the Modality of Youth and Adult Education (PROEJA). It is characterized as exploratory and descriptive research, based on a qualitative and dialectic perspective and the bibliographic technique. It is organized in 02 (two) sections: a) it addresses the conceptual bases of the IF, emphasizing research as a pedagogical principle; b) presents the analysis of an account of teaching experience with research in the context of PROEJA. It is concluded that classroom research is inseparable from teaching. Thus, it is necessary to create effective spaces in PROEJA so that students can deal with elements inherent to research such as questioning, the construction of arguments, written production and dialogue.
\end{abstract}

KEYWORDS: Research. Youth and Adult Education. Teaching.

\title{
La investigación como principio pedagógico en el contexto de PROEJA
}

\section{RESUMEN}

Este estudio tiene como objetivo comprender los fundamentos que guían a los Institutos Federales de Educación, Ciencia y Tecnología (IF), a fin de comprender las bases conceptuales de la investigación como principio pedagógico en el contexto del Programa para la Integración de la Educación Profesional a la Escuela Secundaria en la Modalidad de Educación de jóvenes y adultos (PROEJA). Se caracteriza por ser una investigación exploratoria y descriptiva, basada en una perspectiva cualitativa y dialéctica y en la técnica bibliográfica. Está organizado en 02 (dos) secciones: a) aborda las bases conceptuales de la FI, enfatizando la investigación como un principio pedagógico; b) presenta el análisis de un relato de experiencia docente con investigación en el contexto de PROEJA. Se concluye que la investigación en el aula es inseparable de la enseñanza. Por lo tanto, es necesario crear espacios efectivos en PROEJA para que los estudiantes puedan lidiar con elementos inherentes a la investigación, como el cuestionamiento, la construcción de argumentos, la producción escrita y el diálogo.

PALABRAS CLAVE: Buscar. Educación de jóvenes y adultos. Enseñando. 


\section{Introdução}

O Programa de Integração da Educação Profissional ao Ensino Médio na Modalidade de Educação de Jovens e Adultos (PROEJA) constitui-se como uma das iniciativas implementadas na contemporaneidade voltada para a educação profissional. O PROEJA, enquanto programa educacional brasileiro foi instituído pelo Decreto $\mathrm{n}^{0} 5.478$ (BRASIL, 2005) e ampliado pelo Decreto $\mathrm{n}^{\circ} 5.840$ (BRASIL, 2006), tenta integrar a educação profissional à educação básica na modalidade de Educação de Jovens e Adultos (EJA).

O PROEJA tem por finalidade oportunizar educação de qualidade e elevar a escolarização de estudantes ${ }^{4}$ que apresentam vulnerabilidades sociais, econômicas, culturais e cognitivas nos processos de inclusão social. Almeja ainda superar a dualidade do trabalho manual e intelectual alienante, por uma perspectiva criadora.

[...] esse programa tem uma proposta diferenciada, objetivando a integração curricular na EJA, a formação de um cidadão mais consciente e crítico de sua realidade, a valorização, o reconhecimento e a inclusão da modalidade de jovens e adultos em instituições de ensino diversas e a construção de uma identidade dos educandos trabalhadores que buscam formação diferenciada para entrar, permanecer ou avançar no mundo do trabalho. (MORAIS, 2015, p. 20).

Contudo, para dar conta desses objetivos há que se pensar práticas educativas para a Educação Profissional e Tecnológica (EPT) (CASTAMAN et al., 2019, CASTAMAN; DE BORTOLI, 2020) que compreendam estratégias de ensinagem ${ }^{5}$ (ANASTASIOU; ALVES, 2015) que favoreçam à permanência e à construção de aprendizagens por parte

\footnotetext{
4 Ressalta-se que a EJA e a Educação Profissional e Tecnológica são modalidades de ensino historicamente destinadas aos trabalhadores.

${ }^{5}$ Anastasiou e Alves (2015) descrevem, 20 estratégias de ensinagem: aula expositiva dialogada, estudo de texto, portfólio, tempestade cerebral, mapa conceitual, estudo dirigido, lista de discussão por meios informatizados, solução de problemas, phillips 66, grupo de verbalização e de observação (GV/GO), dramatização, seminário, estudo de caso, júri simulado, simpósio, painel, fórum, oficina (laboratório ou workshop), estudo do meio e ensino com pesquisa.
} 
dos estudantes. Diante do exposto e de uma experiência realizada no PROEJA, do Instituto Federal de Educação, Ciência e Tecnologia do Rio Grande do Sul (IFRS) - Campus Sertão, empregou-se a estratégia ensino com pesquisa na EPT (VIEIRA et al., 2019), como base para o processo formativo integral dos estudantes. Entende-se que a partir da pesquisa pode-se construir um.

[...] sujeito histórico autossuficiente, crítico e autocrítico, participante, capaz de reagir contra a situação de objeto e de não cultivar os outros como objeto [...] pesquisa como diálogo é processo cotidiano, integrante do ritmo da vida, produto e motivo de interesses sociais em confronto, base da aprendizagem que não se restrinja a mera reprodução; na acepção mais simples, pode significar conhecer, saber, informar-se para sobreviver, para enfrentar a vida de modo consciente. (DEMO, 2011, p. 43).

Sabe-se dos desafios de atuar no PROEJA (FRANZOI et al., 2010), mas acredita-se que nas condições supracitadas, ou seja, a partir de conteúdos voltados para a prática social e de pesquisa, pode-se aproximar os educandos da compreensão da totalidade, em busca de uma formação politécnica, plena e integral. Politecnia aqui entendida como "[...] uma educação que possibilita a compreensão dos princípios científico-tecnológicos e históricos da produção moderna, de modo a orientar os estudantes à realização de múltiplas escolhas”. (RAMOS, 2008, p. 3). Ou seja, uma formação integral que mobiliza o estudante para analisar criticamente a realidade, pela dialética de cada situação concreta.

Assim, este estudo tem por objetivo conhecer os fundamentos que norteiam os Institutos Federais de Educação, Ciência e Tecnologia, de modo a compreender as bases conceituais da pesquisa como princípio pedagógico no contexto do PROEJA. Este estudo caracteriza-se como pesquisa exploratória e descritiva, pautando-se em uma perspectiva qualitativa e dialética. Como técnica contou com a bibliográfica que fundamentou e orientou o trabalho. A pesquisa bibliográfica é “[...] desenvolvida com base em material já elaborado, 
constituído principalmente de livros e artigos científicos”. (GIL, 2002, p. 44). Para conhecer sobre as bases conceituais que norteiam os IF e acerca da pesquisa como princípio pedagógico, verifica-se em Veiga, Resende e Fonseca (2000), Demo (2001, 2015), Lima e Grillo (2008), Martins (2009), Pacheco (2010, 2020), Moraes, Galiazzi e Ramos (2012), Rehfeld (2013), Anastasiou e Alves (2015), Castaman e Hannecker (2017) e em documentos regulatórios, tais como Brasil (2008, 2012, 2015). Para apresentar a discussão e análise do relato da experiência da pesquisa no contexto do PROEJA, pauta-se em Freire (1987, 2013), Pernambuco (2002), Chassot (2003), Haidt (2003), Veiga (2006), Brousseau (2008), Lima e Grillo (2008), Ramos (2010), Thiollent (2011), Cruz e Szymanski (2012), Moll (2012), Rehfeld (2012), Ambrósio (2013), Anastasiou e Alves (2015), Coutinho e Moraes (2015), Demo (2015), Vieira et al. (2019) e em documentos do PROEJA: Brasil (2006, 2007, 2015), IFRS (2011, 2012, 2018) e Castaman (2020).

A estruturação deste trabalho está organizada em 02 (duas) seções: a) aborda as bases conceituais dos Institutos Federais de Educação, Ciência e Tecnologia, enfatizando a pesquisa como um princípio pedagógico; b) apresenta um relato de experiência da pesquisa como princípio pedagógico no contexto do PROEJA. Por fim, são discorridas as considerações finais deste estudo.

\section{Os Institutos Federais de Educação, Ciência e Tecnologia e a pesquisa como princípio pedagógico}

Apesar de uma história centenária da Rede Federal de Educação Profissional, Científica e Tecnológica, os Institutos Federais de Educação, Ciência e Tecnologia (IF) foram implementados a partir da Lei $\mathrm{n}^{0} 11.892$ (BRASIL, 2008). Os IF têm como finalidade a formação profissional, em especial, por meio da oferta de educação profissional integrada ao ensino médio, de um currículo integrado (CASTAMAN; HANNECKER, 2017). 
Tem como objetivos atuar na formação inicial, no ensino médio integrado a formação profissional, na graduação, preferencialmente, tecnológica e na pós-graduação. Entretanto, estas diferentes modalidades têm de dialogar entre si, procurando estabelecer itinerários formativos possibilitando reduzir as barreiras entre os níveis e modalidades, que dificultam a continuidade da formação dos educandos especialmente os oriundos das classes trabalhadoras e excluídos. Preconizam a atuação junto aos territórios e populações com vulnerabilidade social objetivando integrá-las à cidadania e aos processos de desenvolvimento com inclusão. (PACHECO, 2020, p. 07).

O objetivo central do ensino integrado “[...] não é formar um profissional para o mercado de trabalho, mas sim um cidadão para o mundo do trabalho, o qual poderia ser tanto técnico, como filósofo, um escritor ou tudo isso". (PACHECO, 2010, p. 07). Assim, possui como princípios educativos: a formação humana integral, o trabalho como princípio educativo, a prática social como fonte de conhecimentos, a indissociabilidade entre todas as dimensões do processo educativo: ensino, pesquisa e extensão (PACHECO, 2020) e pesquisa como pressuposto pedagógico ${ }^{6}$. Neste escopo, dedica-se, nesta investigação a explorar a pesquisa como pressuposto pedagógico.

Segundo Demo (2015), os meios digitais têm permitido o contato cada vez maior com livros, bibliotecas e bancos de dados, o que facilita o acesso ao conhecimento, estando esse cada vez mais descentralizado. Assim, o autor salienta que a pesquisa pode se caracterizar como um método didático e investigativo para atingir autonomia intelectual e atuar na condição de sujeito capaz de pensar por si e de (re)construir conhecimentos.

Martins (2009, p. 39) alude que o trabalho com pesquisa possibilita que o aluno deixe de ser "[...] ouvinte repetidor de conteúdos e passe a agir e a refletir com consciência crítica diante dos fatos estudados". Implica em um projeto que tem por objetivo efetivar o protagonismo do estudante no processo de construção do conhecimento e conduzir este protagonismo

\footnotetext{
${ }^{6}$ Neste estudo, admite-se a Pesquisa como Princípio Educativo e a Pesquisa como Princípio Pedagógico como sinônimos.
} 
também nos ambientes de trabalho e em demais espaços de interação social. Veiga, Resende e Fonseca (2000, p. 185-186) reforçam que,

[...] O grande destaque à pesquisa parece apoiar-se no entendimento de que a produção do conhecimento é um processo social, que parte de problemas vividos pela sociedade que, uma vez trabalhados pelo pesquisador, transformam-se em problemas e questões a serem respondidas de maneira partilhada, para então retornar à sociedade.

No que concerne à Educação Profissional e Tecnológica (EPT), documentos orientadores do ensino, como as Diretrizes Curriculares Nacionais para a Educação Profissional Técnica de Nível Médio (BRASIL, 2012) e a Base Nacional Curricular Comum (BNCC) (BRASIL, 2015) ampliaram a concepção na pesquisa como princípio pedagógico, reconhecendo que educar pela pesquisa é uma prática de ensino considerada uma premissa necessária no contexto atual. As Diretrizes (BRASIL, 2012) qualificam a pesquisa como princípio pedagógico, orientada e mediada pelos professores, que a remete como um princípio norteador para integrar os saberes específicos à produção do conhecimento e à intervenção social.

A pesquisa como princípio pedagógico exige diálogo crítico e criativo com a realidade, visa a transpor seu escopo para o contexto social mais amplo e caracteriza-se como uma prática constante do "aprender a aprender" (DEMO, 2001) que deve permear o fazer educacional. Para Rehfeld (2013, p. 06), a pesquisa como princípio pedagógico remete a uma condição para "[...] a autonomia intelectual. Por meio da qual, docentes e discentes, na convergência de pensares, buscam respostas para problemas, situações que permeiam o contexto social, cultural, econômico e político". Moraes, Galiazzi e Ramos (2012, p. 10) corroboram, abordando que

A pesquisa em sala de aula é uma das maneiras de envolver os sujeitos, alunos e professores, num processo de questionamento do discurso, das verdades implícitas e explícitas nas formações discursivas, propiciando a partir disso a construção de argumentos que levem a novas 
verdades. A pesquisa em sala de aula pode representar um dos modos de influir no fluxo do rio. Envolver-se nesse processo é acreditar que a realidade não é pronta, mas que se constitui a partir de uma construção humana.

Valer, Brognoli e Lima (2017, p. 2787) enfatizam que a pesquisa como princípio pedagógico, tem por finalidade “[...] desenvolver nos estudantes habilidades cognitivas para interpretar teorias, relacionar, analisar, criticar, refletir, rejeitar ideias fechadas, aprender, buscar soluções, propor alternativas etc.[...]". Anastasiou e Alves (2015) salientam que o ensino com pesquisa oferece condições para que os estudantes adquiram autonomia, assumam responsabilidades, desenvolvam a disciplina e a habilidade de se manter o tempo necessário na busca da solução de problemas até o esgotamento das informações, sendo orientado pelo professor. Demo (2015, p. 05) propõe que ao educar pela pesquisa deve-se considerar quatro pressupostos, ou seja,

- a convicção de que a educação pela pesquisa é a especificidade mais própria da educação escolar, - o reconhecimento de que o questionamento reconstrutivo com qualidade formal e política é o cerne do processo de pesquisa, - a necessidade de fazer da pesquisa atitude cotidiana no professor e no aluno,

- e a de noção de educação como processo de formação da competência histórica humana.

Para Anastasiou e Alves (2015), alguns princípios são relevantes: o conteúdo é tomado como provisório, datado e resultado de investigação; novos estudos podem reformular o existente com novas perspectivas. Os critérios para validação do conhecimento são: probabilidade, plausibilidade, demonstração, evidência lógica e empírica. Lima e Grillo (2008) elencam alguns princípios inerentes ao ato de pesquisar, sendo eles: o questionamento, a construção de argumentos, a produção escrita e o permanente diálogo entre situações do cotidiano e conteúdos escolar/acadêmicos.

Viera et al. (2019) marcam que na EPT, a pesquisa deve ser encarada como uma atividade que possibilita construir cientificamente um problema 
que esteja sob foco de análise, levantar hipóteses, argumentar e elaborar teorias e, além disso, despertar a criatividade.

Assim, o rigor cabe tão bem à pesquisa como ao ensino, visto igualmente como um processo criativo e inovador, um espaço para a reflexão, a crítica e a formulação de (novas) propostas, a fim de conseguir que a EPT seja de qualidade, porém com um profundo sentido social e humanista. (VIEIRA et al., 2019, p. 285).

Deste modo, indissociar/articular/imbricar a pesquisa no ensino enquanto prática social e integradora, remete a reformular a lógica do ensino tradicional, adensando em outras possibilidades de ensino e aprendizagem. A partir desta apresentação, a próxima seção aborda o relato de experiência da pesquisa como princípio pedagógico no contexto do PROEJA, em um IF.

\section{PROEJA: um relato de experiência da pesquisa como princípio pedagógico}

O PROEJA, instituído como programa educacional brasileiro pelo Decreto $\mathrm{n}^{\circ} 5.840^{7}$ (BRASIL, 2006), para todas as esferas de ensino, seja estadual, municipal ou federal, surgiu como uma tentativa de integrar a educação profissional à educação básica na modalidade de EJA, a partir de uma educação integral. Para Ramos (2010), o entendimento sobre integração é amplo. Contudo, manifesta uma concepção de formação humana que prioriza todas as dimensões da vida, da cultura, da ciência e do trabalho. A autora enfatiza que o horizonte desta formação é a politécnica e omnilateralidade de trabalhadores, tendo como premissa permitir a compreensão das relações sociais e do processo histórico e contraditório do desenvolvimento das forças produtivas. Logo, por meio dessas bases conceituais entende-se uma possível formação de

\footnotetext{
${ }^{7}$ O referido Decreto deriva de uma ampliação do Decreto 5.478 (BRASIL, 2005), que criou o Programa, contudo limitava sua extensão ao âmbito das instituições federais de educação tecnológica e ao nível médio.
} 
profissionais-cidadãos capazes de conceber e de atuar na realidade. O PROEJA é uma política pública que visa

[...] uma formação integrada do cidadão, a qual consiste não somente na absorção de conhecimentos científicos e profissionais, mas num conhecimento para a vida, para a sua construção pessoal como ser social que se transforma e transforma a sociedade em que se encontra inserido. (COUTINHO; MORAES, 2005, p. 73).

Dito isso, os documentos reguladores e as práticas educativas das Instituições Federais da EPT, necessitam integrar estes elementos formativos. As concepções e as diretrizes do PROEJA no IFRS fundamentam-se na formação integral e omnilateral, além disso oferta 10\% das matrículas em cursos na modalidade PROEJA (IFRS, 2018). O IFRS assume um caráter humanizador no referido curso, de modo a proporcionar

[...] ao jovem e ao adulto o acesso à produção histórica da humanidade e à formação profissional que lhe permita compreender e atuar no mundo na busca de melhorá-lo, o PROEJA propõe uma formação que viabilize ao sujeito inserir-se de modos diversos no mundo do trabalho, inclusive gerando emprego e renda, sem abandonar aspectos de sua vida, como a religiosidade, a família, a participação social, política e cultural, constituindo-se como uma ação contínua na rede pública de ensino.

Articular a escolarização e o trabalho, no contexto do PROEJA, tem um sentido de alargamento de horizontes, promoção da reflexão sobre o processo de trabalho, melhoria nos relacionamentos interpessoais, desenvolvimento da consciência de coletividade, possibilidade de intervenção na realidade e de melhoria da qualidade de vida.

[...] busca proporcionar condições para que todos os cidadãos tenham acesso, permanência e êxito na educação básica pública, gratuita e de qualidade. A Educação de Jovens e Adultos é uma modalidade de ensino com características específicas e isso demanda investimento na formação de professores para que possam entender e melhor atender a todas as questões relativas ao campo teórico que articula a educação profissional e a educação básica na modalidade da educação de jovens e adultos. Sendo esse um público diferenciado, que exige práticas pedagógicas de conscientização e de transformação da realidade, 
é fundamental que as ações docentes valorizem as trajetórias de aprendizagem dos educandos, focando a qualidade dos processos. [...] tem garantido aos estudantes-trabalhadores [...] a inclusão social e a possibilidade de continuidade dos estudos através de um currículo que valoriza os saberes e promove uma prática pedagógica coerente [...]. (IFRS, 2011, p. 43-44).

Neste escopo, no IFRS - Campus Sertão se oferta anualmente, desde 2012, o Curso Técnico em Comércio, na modalidade PROEJA. O curso noturno compreende $2.400 \mathrm{~h}$, em 5 (cinco) módulos de formação básica e profissional e tem por objetivo geral formar profissionais, "[...] em consonância com as demandas dos setores produtivos e da compreensão da realidade, a partir da mediação dos conceitos já elaborados, o aprender a conhecer, aprender a ser, numa perspectiva política, social e cultural”. (IFRS, 2012, p. 11).

A unidade curricular de "Recursos Humanos e Relações Interpessoais", consta no primeiro semestre e totaliza uma carga horária de 80h. Tem como finalidade "Proporcionar embasamento teórico e prático para que o aluno possa melhor compreender as relações interpessoais nos diversos ambientes e conhecer atividades relacionadas aos procedimentos da gestão de pessoas na organização" (IFRS, 2012, p. 28), a partir de conteúdos voltados para a prática social. Conforme dados do Plano de Ensino (CASTAMAN, 2019), a metodologia está sustentada

[...] na concepção de aprendizagem da Teoria Histórico Cultural, num processo de interação, discussão e sistematização a partir de estudo teórico. Assim, serão realizadas leituras preparatórias e complementares, discussões de textos e livros, pesquisas, aulas expositivo-dialogadas, estudos de casos, sistematizações individuais e no coletivo.

Pauta-se, em linhas gerais na Metodologia da Mediação Dialética (MMD), na qual se considera,

[...] além do saber cotidiano do aluno, o seu desenvolvimento como ser histórico e social, [...] centrada nos processos de ensino (desenvolvido pelo professor), de aprendizagem (desenvolvido pelo aluno) e principalmente na relação entre 
ambos. Tem como eixo central a mediação pedagógica, a relação dialética que se estabelece entre professor e aluno, entendidos como seres sociais que desenvolvem a aula e, nela, se desenvolvem. (CRUZ; SZYMANSKI, 2012, p. 456).

Assim, há que se "[...] garantir aprendizagens e reinventar o modo de organização dos tempos, espaços e lógicas que presidem os processos escolares, superando o caráter discursivo e abstrato, predominante nas práticas escolares" (MOLL, 2012, p. 133). Para tanto, uma das principais estratégias de ensinagem empregada foi a pesquisa como um princípio pedagógico, visto que se entende que o estudante/trabalhador necessita ser estimulado à educação científica, para que de maneira integrada, possa estabelecer relações entre a realidade prática e os conceitos científicos mediados em sala de aula. Chassot (2003), entende que a educação científica é considerada uma das habilidades essenciais do século XXI, ou seja, fundamental para o desenvolvimento pleno do estudante, tanto no âmbito dos desempenhos cognitivos como na preparação à cidadania. Dessa forma, ao aprender a ler a realidade, o estudante poderá conseguir a emancipação.

Ao assumir como premissa a pesquisa enquanto princípio pedagógico para o ensino, pode-se fomentar a educação científica na EPT. Assim, os estudantes serão capazes de (des)construir conhecimentos, sendo a autoria dos mesmos a condição sine qua non para o aprender, para relacionar o conhecimento científico com a realidade concreta. Freire (2013, p. 30-31) reforça:

Não há ensino sem pesquisa e pesquisa sem ensino. Esses que-fazeres se encontram um no corpo do outro. Enquanto ensino contínuo buscando, reprocurando. Ensino porque busco, porque indaguei, porque indago e me indago. Pesquiso para constatar, constatando, intervenho, intervindo, educo e me educo. Pesquiso para conhecer e o que ainda não conheço e comunicar ou anunciar a novidade.

O ensino com pesquisa na Unidade Curricular foi empregado em inúmeras atividades. Vieira et al. (2019, p. 287) explicitam que "há diferentes 
formas de trabalhar a articulação entre ensino e pesquisa na EPT". Sabe-se que a BNCC (BRASIL, 2015) sugere que o estudante registre o percurso de um trabalho de pesquisa por meio de um relatório científico e produza textos de divulgação de conhecimento como artigos. Contudo, nesta ação educativa, em função do perfil da turma ${ }^{8}$ o registro materializou-se na construção de um trabalho acadêmico nomeado como Portfólio. De acordo com Anastasiou e Alves (2015, p. 19), “[...] o portfólio se apresenta como o mais completo: propicia ao professor verificar de forma imediata as dificuldades que o estudante possa estar apresentando e propor soluções para sua superação”.

A atividade do Portfólio foi desenvolvida da primeira à última aula da Unidade Curricular e ainda, constou como um dos instrumentos de avaliação, baseando nos seguintes critérios, conforme sugere Anastasiou e Alves (2015): organização e cientificidade da ação de professor e de estudante; clareza de ideias na produção escrita; construção e reconstrução da escrita; objetividade na apresentação dos conceitos básicos; envolvimento e compromisso com a aprendizagem. Ambrósio (2013) alude que avaliar a aprendizagem pelo Portfólio transforma as relações pedagógicas, porque minimiza as marcas de uma avaliação ansiogênica.

Para tanto, entregou-se no início do semestre, aos estudantes, cadernos, folhas, pastas, entre outros materiais, de modo que cada um pudesse construir seu Portfólio manualmente. Instruiu-se que escrevessem individualmente conceitos, procedimentos, atitudes e refletissem acerca dos mesmos; que incluíssem os rascunhos, porque apresenta um panorama dos esforços, do desenvolvimento e do crescimento da ação. Além disso, recomendou-se que incluíssem fotos e/ou desenhos que representassem como cada temática estava atrelada em sua vida e como estas ilustrações poderiam contribuir para a transformação social. Freire (1987) admite que é preciso

\footnotetext{
8 Trata-se de 25 jovens e adultos - estudantes/trabalhadores, sendo a maioria em situações de vulnerabilidade. Muitos não possuem computador ou mesmo nunca o acessaram. Ainda, ressalta-se que, em torno de $60 \%$ da turma, parou os estudos quando jovem e retornaram para concluir anos depois. Essa caracterização dificulta um relatório final formal, como é indicado para a demonstração dos resultados da pesquisa. Porém, almejou-se inspirá-los a práticas de pesquisa e de investigação, assim como promover a curiosidade, adequando o relato formal a um trabalho que retratasse as subjetividades e os avanços e os desafios de cada um na construção do seu conhecimento.
} 
partir da realidade dos educandos, propondo temas geradores oriundos de pesquisas, trazendo a vida cotidiana e a atualidade dos sujeitos.

Além disso, ocorreram leituras dirigidas em sala de aula e pesquisas em livros e periódicos na biblioteca escolar, participação em aulas expositivodialogadas e, inúmeras vezes, os estudantes foram conduzidos ao Laboratório de Informática do IFRS - Campus Sertão para que, a partir do meio digital, pudessem realizar pesquisas bibliográficas sobre assuntos relevantes, que viessem a agregar na construção do Portfólio. Os estudantes levantaram dados, exploraram, questionaram, analisaram, compararam, criticaram, avaliaram, sintetizaram, argumentaram a partir de conteúdos disponibilizados em base de dados, sites de jornais, periódicos, blogs, entre outros.

O trabalho de pesquisa no Laboratório de Informática era realizado individualmente, com um aluno por computador, e/ou de modo colaborativo, conforme o grau de dificuldade de acesso de cada estudante às ferramentas disponíveis. A dinâmica desenvolvida no Laboratório promoveu um ambiente cooperativo e solidário, o que otimizou os trabalhos individuais e fez com que cada estudante não se sentisse desamparado diante de suas dificuldades. Algumas informações coletadas eram copiadas e salvas em pen drive e outras eram anotadas e transcritas no caderno do estudante para uso posterior. Demo (2015) afirma que quando o estudante passa a ser o protagonista de sua pesquisa, acaba sendo independente quanto às suas escolhas e não apenas um copiador.

Para relatar uma das pesquisas empreendidas, apresentou-se uma situação concreta relacionada aos recursos humanos, ou seja, conflito entre colegas no ambiente de trabalho. Para Brousseau (2008, p. 20), uma situação de aprendizagem implica em:

[...] um modelo de interação de um sujeito com um meio determinado. O recurso de que esse sujeito dispõe para alcançar ou conservar um estado favorável nesse meio é um leque de decisões que dependem do emprego de um conhecimento preciso. Consideramos o "meio" como subsistema autônomo, antagônico ao sujeito. Assim, ao tomarmos como objeto de estudo as 
circunstâncias que regem a difusão e a aquisição dos conhecimentos, vamos nos interessar pelas situações.

Após definir-se conjuntamente o objeto de estudo e pesquisa, cada estudante realizou pesquisas para compreender os conceitos que envolviam a temática. O processo de pesquisa ocorreu por meio de algumas etapas dialógicas. Pernambuco (2002) situa-as como: estudo da realidade (ER), organização do conhecimento (OC) e aplicação do conhecimento (AC).

A atitude problematizadora mobilizou para a curiosidade e o estudo da realidade. Durante a ação educativa, foram empreendidos questionamentos sobre a temática, enquanto um 'chamamento' para conduzir a pesquisa. Lima e Grillo (2008) reforçam que para o êxito da pesquisa é necessário que o docente tenha clareza da finalidade da proposta, ainda, que desafie os estudantes a partir de questionamentos e de argumentações, à pesquisa e à produção escrita, de modo a valorizar o conhecimento escolar e a vivência do educando. A pergunta é um recurso relevante para mediar o estudante no processo de construção do conhecimento. Vieira et al. (2019, p. 282) pontuam que "A construção de atitudes investigativas, questionadoras, é intenção prioritária da prática do ensino com pesquisa”.

Outrossim, a análise dos dados coletados durante toda a trajetória da pesquisa pautou-se no entendimento da realidade. Desta forma, sugeriu-se que cada estudante pudesse fazer incursões de análise conjuntural do fenômeno; examinar o impacto nas relações dentro do ambiente de trabalho e nas relações interpessoais; analisar as influências deste na vida humana; identificar outros desdobramentos e, no final; apresentar possíveis soluções.

Após essas atividades, recomendou-se que o estudante sistematizasse todo o conhecimento construído no Portfólio. Por fim, foi organizado um seminário para socialização (HAIDT, 2003), de modo que os estudantes pudessem expor e debater crítico e reflexivamente o que aprenderam e como este conhecimento poderia ser aplicado na sua realidade. Veiga (2006, p. 106) reforça que o seminário é um "congresso científico, cultural ou 
tecnológico”, que propicia a cooperação, a sociabilidade, o diálogo, a reflexão e a troca de conhecimentos e de experiências.

\begin{abstract}
A partir do conjunto de informações processadas, o seminário produz material. Parte deste material é de natureza "teórica" (análise conceitual, etc.), outra parte é de natureza empírica (levantamentos, análise da situação, etc.). Outra parte ainda, às vezes elaborada com colaboradores externos, é o material de divulgação, de natureza didática ou informativa, destinado ao conjunto da população implicada nos problemas abordados. (THIOLLENT, 2011, p. 67-68).
\end{abstract}

Durante todo o processo, temas como relações de poder, ética, responsabilidade, comprometimento, liderança, entre outros, foram fomentados. Nesta situação de aprendizagem, pode-se salientar o professor enquanto um mediador do processo. Um sujeito com conhecimentos amplos e significativos que media, orienta e acompanha sistemática e atentamente e contribui para que o estudante reconheça, compreenda e analise a realidade.

A mediação do professor é fundamental, pois, ao mesmo tempo em que o aluno precisa reconhecer sua própria autoria no projeto, ele também precisa sentir a presença do professor, que ouve, questiona e orienta, visando propiciar a construção de conhecimento do aluno. A mediação implica a criação de situações de aprendizagem que permitam ao aluno fazer correções necessárias uma vez que os conteúdos envolvidos no projeto precisam ser sistematizados para que os alunos possam formalizar os conhecimentos colocados em ação. (REHFELD, 2012, p. 29).

Ressalta-se que todos os estudantes frequentes na Unidade Curricular entregaram o Portfólio, participaram assiduamente das pesquisas e apresentaram o seminário, o que reflete a motivação dos mesmos na construção do seu conhecimento, mesmo diante das adversidades e das vulnerabilidades que grande parte do grupo dos estudantes/trabalhadores vivencia. O Portfólio de cada estudante representou as suas condições de refletir acerca dos assuntos propostos e 
expressou o conhecimento (re)construído, a partir de produções de complexidades diversas. De toda forma, considerou-se na avaliação a participação e a construção autoral de cada estudante. Assim, a partir da observação sistemática da docente responsável foi possível analisar que diante deste percurso de pesquisa preciso, sequencial, rigoroso, investigativo e que considera os conhecimentos prévios e contextuais dos estudantes, colaborou-se na promoção de uma formação autônoma, crítica e criativa dos estudantes do PROEJA. Os estudantes foram capazes de aprender a aprender, de problematizar, de ter atitudes analíticas e reflexivas a partir de suas próprias observações, de indagar a realidade, de participar ativamente da construção de suas aprendizagens e, especialmente, compreender que o conhecimento é provisório.

Apesar de não ter sido realizado uma avaliação formal com entrevista ou questionário das contribuições da atividade de pesquisa na formação dos estudantes, observou-se que a partir da mesma, os mesmos tiveram uma avanço significativo ao longo do semestre nas práticas de investigação, de leitura e de escrita, bem como no uso das TIC. Ainda, percebeu-se que houve uma melhora nas habilidades de comunicação e apresentação oral de trabalhos, no diálogo, na capacidade de reflexão e de promoção de soluções para as situações concretas. Frisa-se que as produções desenvolvidas evidenciam o crescimento individual e coletivo fomentado pela atividade, em comparação com outras turmas que não tiveram o desenvolvimento desta proposta.

Outro ponto não aprofundado neste estudo, mas que merece ser mencionado remete a interdisciplinaridade e a integração. Apesar da ação educativa ter sido promovida, especialmente, na Unidade Curricular de Recursos Humanos e Relações Interpessoais, houve a parceria de outros componentes curriculares, tais como Língua Portuguesa e Informática Aplicada, que contribuíram com técnicas e estratégias de leitura e de escrita e com letramento às tecnologias da informação e da comunicação (TIC). Nas aulas de Informática Básica, o professor abordou o 
gerenciamento e uso do e-mail e das ferramentas de edição de texto e de apresentações. Ainda, enfatizou formas de otimizar pesquisas na internet, através de ferramentas de busca e navegadores, que são programas que permitem aos usuários inter-relacionarem-se com documentos HTML (HyperText Markup Language). A Unidade Curricular de Língua Portuguesa trabalhou a leitura de textos e o emprego da gramática adequadamente na redação. Destarte, cada componente curricular na data e no horário disponibilizado pelo curso e por meio dos conteúdos de seu ementário, contribuiu de forma significativa com o trabalho de pesquisa, direcionando o desenvolvimento das atividades e possibilitando um melhor aproveitamento dos recursos disponíveis. Do ponto de vista dos estudantes, as aulas de Informática Básica e Língua Portuguesa, tornaram-se mais atrativas, uma vez que os temas abordados nas aulas eram de seu interesse e os conhecimentos foram ampliados de maneira aplicada.

Em consonância com o documento base do PROEJA (BRASIL, 2007), a ideia central foi buscar formas de superar a matriz disciplinar rígida e adotar uma base articuladora, por meio de um componente curricular, que fez o papel integrador e de eixos temáticos. Dito de outro modo, houve uma articulação teórico-prática de caráter ético-político que vinculou o trabalho intelectual às atividades práticas e/ou experimentais, permitindo assim, condições de emancipação, de permanência, de sucesso e de progressão aos estudantes e efetivando a qualidade da EPT. Não obstante, o ensino com pesquisa será adotado em todos os semestres na Unidade Curricular, porque entende-se que humanizou o processo de ensino e aprendizagem ao considerar os contextos, as histórias e as composições concretas(os) de cada estudante, promovendo ao mesmo tempo, o desenvolvimento de habilidades e de atitudes. Quiçá, poderá se tornar um eixo nucleador de toda a estrutura curricular, traduzindo o diálogo, a elaboração e as concepções do coletivo para fomentar o perfil profissional descrito no Projeto Pedagógico de Curso. 


\section{Considerações finais}

Este relato almejou alargar o debate do princípio ensino com pesquisa no PROEJA. Ainda, apresentar a integração curricular de "Recursos Humanos e Relações Interpessoais" à cultura do sujeito e ao mundo do trabalho, por meio da pesquisa como princípio pedagógico.

A pesquisa em sala de aula está cada vez mais indissociável do ensino e constitui-se enquanto um instrumento de socialização dos conhecimentos produzidos. Assim, há que se prever e criar espaços efetivos no PROEJA para que os estudantes/trabalhadores possam sistematicamente lidar com elementos inerentes a pesquisa como o questionamento, a construção de argumentos, a produção escrita e o diálogo.

Constatou-se que por meio da intervenção desta estratégia de ensinagem houve a possibilidade de discutir temas pertinentes aos estudantes, de modo que cada um pode orientar-se diante de situaçõesproblemas questionando, argumentando e escrevendo, atrelando os conteúdos escolares e à realidade, em um processo promotor de uma formação autônoma, crítica e criativa. Concebe-se que é impossível promover todos os conhecimentos que os estudantes necessitam para resolver situações-problemas, no entanto entende-se que mesmo diante das dificuldades, ações como esta devem ser propostas, já que é possível instrumentalizá-los e desenvolver capacidades e habilidades que permitam a problematização e o encontro de algumas soluções para as referidas situações e/ou para aplicação em novos eventos. Assim, a construção da aprendizagem aconteceu pelo processo de pesquisa, a partir da valorização da ação reflexiva e o grande desafio foi arquitetar a unidade curricular enquanto um laboratório de aprendizagem, no qual os estudantes são protagonistas e autônomos, sob o olhar mediador do professor.

Os resultados dessa experiência, que se considerou emblemática, marcam que é possível desenvolver uma prática educativa que articule ensino e pesquisa, sendo esta última uma fonte catalisadora de 
desenvolvimento omnilateral e integral dos estudantes, bem como promove a integração entre escola e comunidade. Contudo, considera-se necessário qualificar o trabalho docente no PROEJA, por meio da formação inicial e continuada para que se possa consolidar o acesso, a permanência e o êxito formativo destes trabalhadores que procuram o IF. Ressalta-se que ainda é necessário amadurecer a pesquisa como princípio pedagógico no contexto do PROEJA e que as ações educativas podem ser fortemente enriquecidas, quando planejadas e trabalhadas de maneira interdisciplinar, a partir de projetos integradores.

Esta atividade foi realizada apenas em uma turma, porém, pretende-se desenvolver em turmas subsequentes e, empreender um comparativo das mesmas, bem como avaliar os impactos na formação de cada estudante. Ainda que não aprofundado neste texto, por suas limitações, salienta-se também que este estudo promove a abertura de reflexões sobre outras temáticas que poderão ser pesquisadas em outras investigações, tais como: interdisciplinaridade, projetos integradores, formação de professores para atuar no PROEJA, estratégias de ensinagem específicas ao PROEJA, impacto na formação dos estudantes a partir de suas percepções, entre outros.

\section{Referências}

AMBRÓSIO, Márcia. O uso do portfólio no ensino superior. 2. ed. Petrópolis: Vozes, 2013.

ANASTASIOU, Léa das Graças Camargos; ALVES, Leonir Pessate. Processos de ensinagem na universidade. Pressupostos para as estratégias de trabalho em aula. 3. ed. Joinville: Univale, 2015.

BRASIL. Decreto $n^{\circ} 5.478$, de 24/06/2005. Institui, no âmbito das instituições federais de educação tecnológica, o Programa de Integração da Educação Profissional ao Ensino Médio na Modalidade de Educação de Jovens e Adultos - PROEJA. Disponível em: http://www.planalto.gov.br/ccivil_03/_Ato20042006/2005/Decreto/D5478.htm. Acesso em: 20 maio 2020. 
BRASIL. Decreto $n^{\circ}$ 5.840, de 13 de julho de 2006. Institui, no âmbito federal, o Programa Nacional de Integração da Educação Profissional com a Educação Básica na Modalidade de Educação Básica na Modalidade de Educação de Jovens e Adultos - PROEJA, e dá outras providências. Disponível em: http://www.planalto.gov.br/ccivil 03/ Ato20042006/2006/Decreto/D5840.htm. Acesso em: 12 maio 2020.

BRASIL. Programa nacional de integração da educação profissional com a educação básica na modalidade de educação de jovens e adultos: documento base. 2007. Disponível em:

http://portal.mec.gov.br/setec/arquivos/pdf2/proeja_medio.pdf. Acesso em: 19 jun. 2020.

BRASIL. Lei $n^{\circ} 11.892$, de 29 de dezembro de 2008. Institui a Rede Federal de Educação Profissional, Científica e Tecnológica, cria os Institutos Federais de Educação, Ciência e Tecnologia, e dá outras providências. Disponível em: http://www.planalto.gov.br/ccivil_03/_Ato20072010/2008/Lei/L11892.htm. Acesso em: 27 maio 2020.

BRASIL. Resolução $n^{\circ}$ 6, de 20 de setembro de 2012. Define Diretrizes Curriculares Nacionais para a Educação Profissional Técnica de Nível Médio. Disponível em: http://portal.mec.gov.br/index.php?option=com docman\&view=download\&al ias=11663-rceb006-12-pdf\&category slug=setembro-2012pdf\&Itemid=30192. Acesso em: 19 jun. 2020.

BRASIL. Base Nacional Curricular Comum: consulta pública em 2015. Brasília: MEC/SEB/DICEI, 2015. Disponível em: http://basenacionalcomum.mec.gov.br/images/BNCC_EI_EF_110518_versaof inal_site.pdf. Acesso em: 27 maio 2020.

BROUSSEAU, Guy. Introdução ao estudo das situações didáticas: Conteúdos e métodos de ensino. São Paulo: Ática, 2008.

CASTAMAN; Ana Sara; HANNECKER, Lenir Antonio. Currículo Integrado: pensando o ensino integrado nos Institutos Federais de Educação, Ciência e Tecnologia no Brasil. Revista de Estudos e Pesquisas sobre Ensino Tecnológico - EDUCITEC, Manaus, v. 3, n. 5, 2017.

CASTAMAN, Ana Sara. Plano de Ensino da Unidade Curricular de Recursos Humanos e Relações Interpessoais. Instituto Federal de Educação, Ciência e Tecnologia do Rio Grande do Sul - Campus Sertão. 2019. Mimeo.

CASTAMAN, Ana Sara et al. Práticas pedagógicas inovadoras: considerações de experiências na educação profissional e tecnológica. VIII Anais do Evidosol/Ciltec (Edição 2019), Belo Horizonte, V. 8, n. 1, p. 01-07, nov. 2019. 
CASTAMAN, Ana Sara; DE BORTOLI, Lis Ângela. Práticas Educativas: relato de experiência na unidade curricular de Engenharia de Software. Informática na educação: teoria e prática, Porto Alegre, V. 23, n. 1, p. 32-44, jan./abr. 2020.

CHASSOT, Attico. Alfabetização científica: uma possibilidade para a inclusão social. Revista Brasileira de Educação, n. 22, p. 89-100, jan-abr. 2003.

COUTINHO, Suzana Andréia Santos; MORAES, Lélia Cristina Silveira de. A formação continuada de professores que atuam no PROEJA: ouvindo os sujeitos envolvidos Formação Docente, Belo Horizonte, v. 07, n. 12 , p. $65-82$, jan./jun. 2015.

CRUZ, Jaqueline Zdebski da Silva; SZYMANSKI, Maria Lidia Sica. O ensino da matemática nas escolas do campo por meio da Metodologia da Mediação Dialética. Práxis Educativa, Ponta Grossa, v. 7, n. 2, p. 445-465, jul./dez. 2012.

DEMO, Pedro. Desafios modernos da Educação. 11. ed. Petrópolis: Vozes, 2001.

DEMO, Pedro. Pesquisa: princípio científico e educativo. 14. ed. São Paulo: Cortez, 2011.

DEMO, Pedro. Educar pela pesquisa. 10. ed. Campinas, SP: Autores associados, 2015.

FRANZOI, Naira Lisboa et al. Escola, saberes e trabalho: a pesquisa do PROEJA no Rio Grande do Sul. Revista Educação e Realidade, Porto Alegre, v 35, n. 1, p. 167- 186, 2010.

FREIRE, Paulo. Pedagogia do Oprimido. Rio de Janeiro: Paz e Terra, 1987.

FREIRE, Paulo. Pedagogia da autonomia: saberes necessários à prática educativa. 44. ed. Rio de Janeiro: Paz e Terra, 2013.

GIL, Antonio Carlos. Como elaborar projetos de pesquisa. 4. ed. São Paulo: Atlas, 2002.

HAIDT, Regina Célia Cazaux. Curso de Didática Geral. São Paulo: Ática, 2003.

IFRS - Instituto Federal de Educação, Ciência e Tecnologia do Rio Grande do Sul - Campus Sertão. Projeto pedagógico de curso técnico em comércio: modalidade PROEJA. 2012. Disponível em: https://ifrs.edu.br/sertao/wpcontent/uploads/sites/7/2019/09/PPC-PROEJA-em-Com\%C3\%A9rcio2012.pdf. Acesso em: 18 jun. 2020. 
IFRS - Instituto Federal de Educação, Ciência e Tecnologia do Rio Grande do Sul. Projeto Pedagógico Institucional. Disponível em:

https://arquivo.ifrs.edu.br/site/midias/arquivos/201226102555931ppi versao final.pdf. Acesso em: 19 jun. 2020.

IFRS - Instituto Federal de Educação, Ciência e Tecnologia do Rio Grande do Sul. Plano de desenvolvimento institucional 2019-2023. Aprovado pelo Conselho Superior, conforme Resolução n ${ }^{0}$ 84, de 11 de dezembro de 2018. Disponível em: https://ifrs.edu.br/wp-content/uploads/2019/07/PDI-FINAL2018_Arial.pdf. Acesso em: 19 jun. 2020.

LIMA, Valderez Marina do Rosário; GRILLO, Marlene Correro. A pesquisa em sala de aula. In: FREITAS, Ana Lúcia Souza de (Org.). A gestão da aula universitária na PUCRS. Porto Alegre: EDIPUCRS, 2008, p. 89-98.

MARTINS, Jorge Santos. O trabalho com projetos de pesquisa: do ensino fundamental ao ensino médio. 6. ed. Campinas: Papirus, 2009.

MOLL, Jaqueline. Caminhos da educação integral no Brasil: direito a outros tempos e espaços educativos. Porto Alegre: Penso, 2012.

MORAIS, Ariadiny Cândido. Prática pedagógica e formação dos professores da educação profissional na relação com concepções e princípios do PROEJA. 2015. 157f. Dissertação (Mestrado em Educação) - Programa de PósGraduação em Educação da Faculdade de Educação, Universidade Federal de Goiás, Goiânia, 2015.

MORAES, Roque; GALIAZZI, Maria do Carmo; RAMOS, Maurivan G. Pesquisa em sala de aula: fundamentos e pressupostos. In: MORAES, Roque; LIMA, Valderez Marina do Rosário (org). Pesquisa em sala de aula: tendências para a educação em novos tempos. 3. ed. Porto Alegre: EDIPUCRS, 2012, p. 11-20.

PACHECO, Eliezer. Os Institutos Federais: Uma revolução na educação profissional e tecnológica. Natal: IFRN, 2010.

PACHECO, Eliezer. Desvendando os Institutos Federais: identidade e objetivos. Educação Profissional e Tecnológica em Revista, Vitória, v. 4, n. 1, 2020, p. 1-19.

PERNAMBUCO, Marta Maria C. A. Significações e realidade: conhecimento. In: PONTUSCHKA, Nidia Nacib (Org.). Ousadia no diálogo: interdisciplinaridade na escola pública. 4. Ed. São Paulo: Loyola, 2002.

RAMOS, M. Concepção do ensino médio integrado, 2008. Disponível em: http://forumeja.org.br/go/sites/forumeja.org.br.go/files/concepcao_do_ensino_ medio_integrado5.pdf. Acesso em: 14 maio 2020. 
RAMOS, Marise Nogueira. Implicações Políticas e Pedagógicas da EJA Integrada à Educação Profissional. Revista Educação e Realidade, Porto Alegre, v 35, n. 1, p. 65- 86, 2010.

REHFELD, Waldi Orlando. Pesquisa como princípio pedagógico: implantação do componente seminário na Escola Estadual de Ensino Médio Dr. Roberto Löw de Nova Ramada/RS. 2013. Disponível em: https://bibliodigital.unijui.edu.br:8443/xmlui/bitstream/handle/123456789/1 399/A\%20Monografia\%20Final\%2010\%20de\%20Dezembro.pdf?sequence=1\& isAllowed=y. Acesso em: 18 jun. 2020.

THIOLLENT, Michel Jean Marie. Metodologia da pesquisa-ação. São Paulo: Cortez, 2011.

VALER, Salete; BROGNOLI, Ângela; LIMA, Laura. A Pesquisa Como Princípio Pedagógico na Educação Profissional Técnica de Nível Médio para a Constituição do Ser Social e Profissional. Fórum Linguístico, Florianópolis, v. 14, n. 4, p. 2785-2803, out./dez., 2017.

VEIGA, Ilma Passos Alencastro; RESENDE, Lúcia Maria Gonçalves de; FONSECA, Marília. Aula universitária e inovação. In: VEIGA, Ilma Passos Alencastro; CASTANHO, Maria Eugênia L. M. (orgs.). Pedagogia universitária: a aula universitária em foco. Campinas (SP): Papirus, 2000. p. 161-191.

VEIGA, Ilma Passos Alencastro. (Org). Técnicas de ensino: novos tempos, novas configurações. Campinas: Papirus, 2006.

VIEIRA, Josimar de Aparecido et al. Ensino com pesquisa na educação profissional e tecnológica: noções, perspectivas e desafios. Revista Tempos e Espaços em Educação, São Cristóvão, Sergipe, Brasil, v. 12, n. 29, p. 279-298, abr./jun. 2019. 